\title{
FOTOINTERPRETAÇÃO GEOLÓGICA DE IMAGENS MULTIFONTES E SUA APLICAÇÃO NO GREENSTONE BELT RIO DAS VELHAS, QUADRILÁTERO FERRÍFERO, MG
}

\author{
ALEXANDRE DE AMORIM TEIXEIRA ${ }^{1,2}$, ADALENE MOREIRA SILVA ${ }^{3}$, AUGUSTO CÉSAR $^{2}$ \\ BITTENCOURT PIRES ${ }^{2}$, ROBERTO ALEXANDRE DE MORAES ${ }^{2}$ \\ \& CARLOS ROBERTO DE SOUZA FILHO ${ }^{3}$
}

\begin{abstract}
Resumo O presente trabalho apresenta os resultados baseados nas técnicas de interpretação geológica de dados multifontes, oriundos de aerogeofísica, de sensoriamento remoto e do modelo digital de elevação do terreno da região do projeto Rio das Velhas, Quadrilátero Ferrifero. Os melhores produtos resultantes do processamento digital de imagens multifontes para interpretação geológica são os resultantes de cromoestereoscopia e transformação IHS das imagens aerogeofísicas com a primeira componente principal do ETM+/Landsat 7 ou a imagem de radar ou a banda pancromática do ETM+/Landsat 7 ou o Modelo Digital de Elevação sombreado no canal de intensidade. A interpretação geológica dessas imagens permite a individualização de 57 unidades litogeofísicas que apresentam diferentes comportamentos de acordo com a análise das propriedades texturais e forma da rede de drenagem, caracterização das formas de relevo, análise das propriedades de textura das estimativas de profundidade de fontes magnéticas por deconvolução de Euler-3D, intensidade dos canais aerogeofísicos e elementos de textura do relevo de radar e de textura do relevo magnético. Estes produtos possibilitam a extração de feições lineares do relevo e do relevo magnético de estruturas interpretadas como direcionais, lineamentos indiferenciados, lineamentos de relevo magnético e estruturas como a zona de cisalhamento São Vicente.
\end{abstract}

Palavras-chave: fotogeologia, processamento digital de imagens, Greenstone Belt Rio das Velhas, geofísica aérea, sensoriamento remoto.

\begin{abstract}
MULTI-SOURCE IMAGE GEOLOGIC INTERPRETATION AND ITS APLICATTION TO THE GREENSTONE BELT RIO DAS VELHAS, QUADRILATERO FERRIFERO. This paper presents the results based on state of art of geologic interpretation techniques applied to airborne geophysical data, remote sensing and digital elevation model (DEM) from the Rio das Velhas Project, Quadrilátero Ferrifero and their data integration products. The best products resulting from the digital image processing of multisource data are: chromo stereoscopy and IHS Fusion of airborne geophysical images with the first principal component of ETM+/Landsat7 or radar image; or ETM+/Landsat7 panchromatic band or shaded digital elevation model as intensity channel. The geologic interpretation of this integrated images allows the individualization of 57 lithogeophysical units that presents different characteristics according to the analysis of the stream drainage patterns, characterization of landforms, analysis of textural properties of depth estimates of magnetic sources by Euler deconvolution-3D, airborne geophysical channels intensity and radar texture elements of relief and magnetic relief texture. These products allow the delineation of linear relief features and linear magnetic relief features named as directional, indifferent lineaments, magnetic relief lineament and structures associated with the São Vicente shear zone.
\end{abstract}

Keywords: photogeology, digital image processing, Rio das Velhas Greenstone Belt, airborne geophysical data, remote sensing

\begin{abstract}
INTRODUÇÃO Rivereau (1970) e Soares \& Fiori (1976) propuseram o método da Lógica Sistemática como uma técnica utilizadas para fotointerpretação geológica a partir de fotografias aéreas. Com o surgimento de imagens orbitais de baixa a média resolução espacial, como o sensor MSS/Landsat, viu-se a necessidade de se adaptar esse método para imagens orbitais. Veneziani \& Anjos (1982) propõem um novo método de fotointerpretação geológica a partir de imagens MSS/Landsat. No que se refere à fotointerpretação de imagens de radar, destacam-se os trabalhos desenvolvidos durante o Projeto RADAM (Liu \& Rodrigues, 1985, Lima, 1989, 1995) e, mais recentemente, o trabalho de Ford et al. (1998).

A fotointerpretação de imagens aerogeofísicas normalmente baseia-se na interpretação qualitativa de domínios magnetométricos, gamaespectrométricos ou condutivos. Os produtos derivados do campo magnético anômalo apresentam lineamentos que podem representar estruturas geológicas como fraturas ou falhas ou traços de acamamento, foliação, etc.
\end{abstract}

A estimativa de profundidade de fontes magnéticas, calculada pela deconvolução de Euler, auxilia na interpretação de estruturas geológicas e seu comportamento em subsuperfície, complementando assim a interpretação das estruturas.

A composição colorida falsa-cor dos canais gamaespectrométricos como $\mathrm{K}$, Th e $\mathrm{U}$ permite a diferenciação de domínios que representam unidades litológicas diferentes. Classificam-se os domínios de acordo com a intensidade de radiação do canal, normalmente classificados em baixo, médio ou alto. Pode-se ainda relacionar a esses domínios gamaespectrométricos a intensidade da amplitude do sinal analítico e do canal condutivo (este tipo de fotointerpretação geofísica é mais utilizado na comunidade científica) e, nesse sentido, ressaltam-se os trabalhos de Ferreira et al. (1993), Nash et al.(1996), Duarte (1998), Blum (1999), Silva (1999) e Rolim (2001).

Silva (1999) propõe o conceito de unidade litogeofísica, onde tais unidades representam domínios geofísicos interpretados a partir de dados geofísicos diferenciados. Mapa litogeofí-

1 - Agência Nacional de Águas - ANASPO - Setor Policial Área 5 Quadra 3 Bloco B, sala 103 - CEP: 70610-200 - Brasília - DFalexandre.amorim@ana.gov.br 2 - Universidade de Brasília - Instituto de Geociências - IG/UnBCampus Universitário Darcy Ribeiro - Asa Norte - CEP 70910-900 - Brasília - DFacbpires@unb. brrmoraes@unb.br

3 - Universidade Estadual de Campinas- Instituto de Geociências - IG/UnicampR. João Pandiá Calógeras, 51 - CEP: 13083-970 - Campinas - SPadalene@ige. unicamp.brbeto@ige.unicamp.br 
sico define-se como o mapa que conjuga domínios que possam representar unidades geofísicas e lineamentos magnéticos, ou seja, após validação representam um mapa pré-etapa de campo, sendo o primeiro passo para a cartografia geológica através de dados multifontes.

A fotointerpretação de imagens integradas multifontes, utilizada e proposta neste trabalho, é baseada na conjunção dos métodos já existentes na literatura, porém levando em conta os princípios físicos de cada dado utilizado. Os principais produtos interpretados são provenientes do processamento digital de imagens utilizando a transformação IHS.

Normalmente colocam-se as imagens que realçam a textura do relevo no canal de intensidade, como imagem de radar, banda do infra-vermelho próximo, primeira componente principal de bandas multiespectrais ou modelo digital de elevação (DEM). A imagem no espaço RGB transformada pode ser uma imagem pseudocor dos canais gamaespectrométricos individuais, campo magnético anômalo, ou seus produtos derivados, e o canal de condutividade. Também pode-se utilizar as composições coloridas falsa-cor como as composições RGB/K, Th e U ou RGB/ TM7, TM4 e TM3. Assim, as formas de relevo e drenagem, caracterizadas pelas texturas e tons de imagens de sensores remotos, juntamente com a identificação de anomalias ou assinaturas geofísicas e estruturas regionais fornecem a separação de domínios com características específicas. Nesse sentido, destacam-se os trabalhos de Rivard et al. (1994), Paradella et al. (1997), Reeves et al. (1997), Paradella et al. (1998), Duarte (1998), Paradella et al. (2000), Fuck (2000) e Pedroso et al. (2001).

Para este trabalho, com base em Soares \& Fiori (1986), divide-se a fotointerpretação em três etapas: fotoleitura, fotoanálise e fotointerpretação.

A fotoleitura consiste no conhecimento dos princípios físi$\cos$ dos sensores remotos e aerogeofísicos e o seu equivalente geológico ou geomorfológico. Além disso, a fotoleitura envolve a compreensão e domínio das técnicas de processamento digital de imagens responsáveis pela geração de cada imagem. A fotoanálise envolve a classificação do relevo, da rede de drenagem, dos domínios gamaespectrométricos e dos relevos magnéticos, quanto a sua forma, zonas de repartição e seus limites.

A fotointerpretação compreende a associação dessas zonas homólogas e lineamentos às unidades litoestratigráficas e às estruturas geológicas, respectivamente. Resumindo, a fotointerpretação utilizada nesse trabalho leva em consideração os procedimentos propostos por Veneziani \& Anjos (1982) como a definição de zonas homólogas a partir dos elementos de textura e estrutura das imagens, bem como a utilização do processo dedutivo e indutivo destas zonas em seu significado geológico. Drury (1993) destaca que a interpretação de fotografias ou imagens de satélite para geologia baseia-se nas análises das características de superfície como tonalidade, textura, padrão, forma, contexto e escala que, interpretadas, fornecem a identificação das formas de relevo, dos tipos de rochas e suas relações estratigráficas e estruturais.

MATERIAIS E MÉTODOS Os dados aerogeofísicos utilizados nesse trabalho foram processados por Silva (1999) e, parte deles, reprocessados por Fuck (2001). As linhas de vôo foram orientadas perpendicularmente à direção preferencial das rochas do Supergrupo Rio das Velhas no interior da área (Figura 1) com espaçamento das linhas de vôo de 250 , amarrados por linhas de controle de 5000 metros. Os sensores foram mantidos a uma altura de 60 metros, por sobre a topografia, para o gamaespectrômetro de 45 metros para o magnetômetro/VLF e de 30 metros para o eletromagnetômetro. A taxa média de amostragem do eletromagnetômetro é de \pm 5 metros (5 leituras/segundo), a do magnetômetro é de \pm 5 metros ( 5 leituras/segundo), a do VLF
- EM é de \pm 5 metos (5 leituras/segundo) e, finalmente, o gamaespectrômetro possui taxa de amostragem de \pm 25 metros (1 leitura/segundo). A velocidade de operação do helicóptero utilizado como plataforma esteve entre 70 a $110 \mathrm{~km} / \mathrm{h}$. O eletromagnetômetro empregou três bobinas coplanares com transmissores centrados nas frequências de $500,4.175$ e $33.000 \mathrm{~Hz}$ e duas bobinas coaxiais com 935 e $4600 \mathrm{~Hz}$. O afastamento(transmisor/ receptor) foi de 7 metros.

Os produtos processados do levantamento aerogeofísico consistem nos mapas transformados do campo magnético anômalo: amplitude do sinal analítico de ordem zero, primeira derivada vertical e fase do sinal analítico (Figura 3-D). Dentre os vários mapas eletromagnetométricos, foi utilizado neste trabalho o canal de $4.175 \mathrm{~Hz}$. Segundo Silva (1999), este é o melhor canal para mapear condutores múltiplos e pequenos alvos em profundidade e também exclui a influência antrópica observada no canal de $33.000 \mathrm{~Hz}$. O mapa de resistividade de Fuck (2001) é transformado para condutividade (1/resistividade) onde se tomam os logaritmos destes valores no estudo.

Todos os canais gamaespectrométricos foram utilizados nesse trabalho (canais de contagem total, potássio, equivalente de tório e equivalente de urânio). Por fim, todos os produtos processados por Fuck (2001) tiveram seus valores absolutos (cps, $\mathrm{Hz}, \mathrm{nT}$, etc) convertidos linearmente para 8 bits (256 tons de cinza) e convertidos para o formato geotiff. O pré-processamento, interpolação, micronivelamento e processamento dos dados de Fuck (2001), bem como o reprocessamento desses dados e o cálculo de estimativa de profundidade por deconvolução de Euler foram efetuados no programa Oasis Montaj 5.06.

Um avanço no processamento de dados aerogeofísicos é a aplicação da deconvolução de Euler na tentativa de se compreender o comportamento das fontes magnéticas relevantes e sua relação com arcabouço estrutural e mineralizações associadas.

A deconvolução de Euler-3D proposta por Thompson (1982) visa à localização e cálculo da estimativa de profundidade de diferentes fontes magnéticas simples a partir de dados magnetométricos ou gravimétricos.

A relação de homogeneidade de Euler (Thompson 1982) pode ser expressa na forma:

$$
\left(x-x_{0}\right) \partial T / \partial x+\left(y-y_{0}\right) \partial T / \partial y+\left(z-z_{0}\right) \partial T / \partial z=N(B-T)
$$

onde $\left(x_{0}, y_{0}, z_{0}\right)$ compreende a posição da fonte cujo campo total $T$ é detectado nos pontos $(x, y, z)$ do operador. O campo regional total é denotado pelo valor $B$.

Os tipos de fontes magnéticas são expressos por meio do índice de homogeneidade $N$, interpretados como índices estruturais (SI) onde o índice 0 corresponde a contatos geológicos irregulares, o índice 1 corresponde a limites de soleiras, diques ou falhas, o indice 2 para corpos cilíndricos verticaịs e o índice 3 para corpos esféricos. Os índices intermediários como 0,5 ou 1,5 representam corpos com geometria híbrida dos apresentados.

A estratégia de utilização da deconvolução de Euler-3D proposta por Reid et al. (1990) compreende cálculo dos gradientes

$$
\partial T / \partial x, \partial T / \partial y_{\mathrm{e}} \partial T / \partial z
$$

a determinação do tamanho da janela da malha (operador) a ser calculado; a solução da equação de Euler para todos os pontos da janela; verificação se a incerteza relativa ao cálculo da estimativa de profundidade não é maior que $15 \%$; aplicação do operador deslocando sistematicamente em toda a região coberta com grades de superposição e, finalmente, aplicação deste procedimento para todos os índices estruturais selecionados.

Para melhor compreender o comportamento em subsuperficie das falhas com assinaturas magnéticas na região aerolevan- 


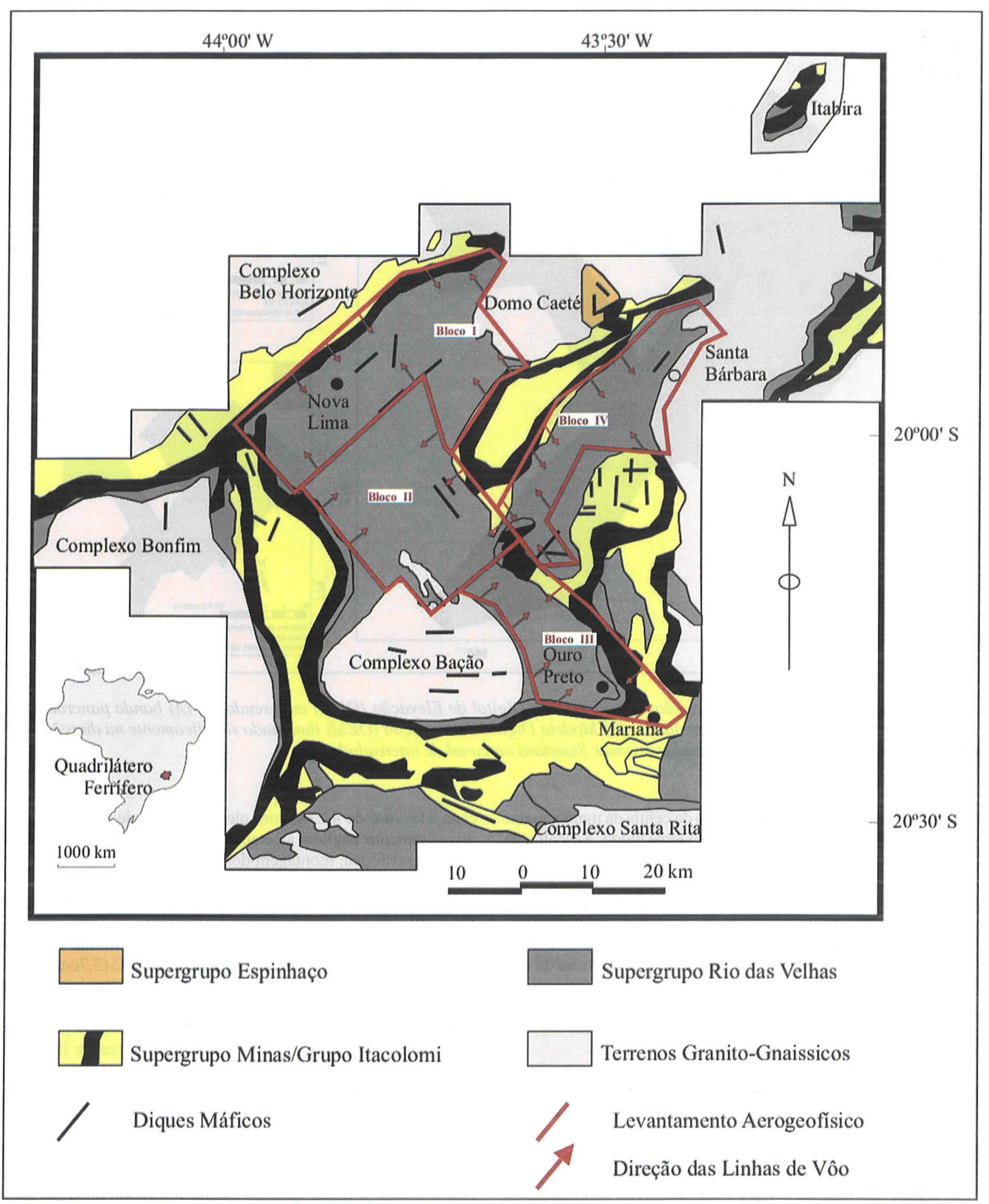

Figura 1 - Mapa geológico do Quadrilátero Ferrífero (Modificado por Silva (1999) de Dorr 1969).

tada do Supergrupo Rio das Velhas, procedeu-se a estimativa das profundidade para fontes magnéticas de índice estrutural 1 , visto que este se aproxima mais do modelo de falha. Seguindo a proposta de Reid et al. (1990), utilizou-se janela de $10 \times 10$ células da malha do campo magnético anômalo com dimensões espaciais de 50,125, 250 e 500 metros. Objetivou-se a determinação de fontes magnéticas em maiores profundidades à medida que se aumenta o tamanho da janela. Para tanto, também se calculou a profundidade das fontes magnéticas com incerteza relativa de 5, 10 e $15 \%$ para todas as malhas. Quanto maior é a 


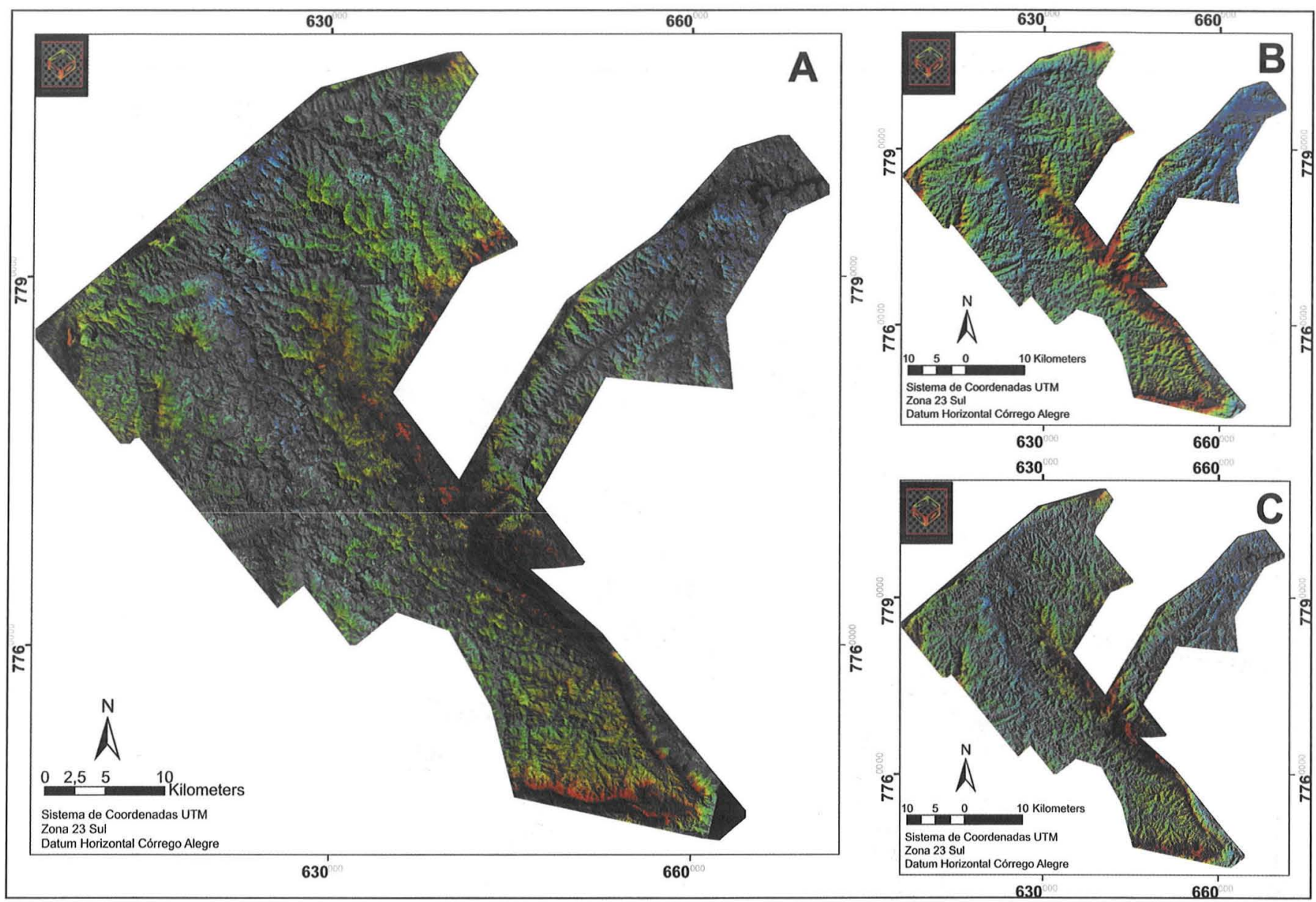

Figura 2 - EDICROM-R - Transformação IHS do Modelo Digital de Elevação (DEM) em pseudocor. (A) banda pancromática do ETM+/Landsat 7 no canal de intensidade, (B) Modelo Digital de Elevação (DEM) iluminado sinteticamente na direção $135^{\circ}$ e elevação $42,23^{\circ}$ e (C) imagem de radar Scansar Standard no canal de intensidade

incerteza relativa e menor é o tamanho da célula da malha, maior é o número de ocorrências calculadas. Desse modo, a escolha da incerteza relativa ao cálculo da ocorrência para cada tamanho de célula visou limitar a grande quantidade de ocorrências gerada pelas células menores e extender o número das ocorrências calculadas pelas células maiores. Assim escolheram-se as ocorrências com incerteza relativa de $5 \%$ para as malhas com células de 50 e 125 metros, limite de $10 \%$ para a malha com células de 250 metros e, por fim, 15\% para a malha com célula de 500 metros. Calcularam-se as estimativas de profundidade de fontes magnéticas por deconvolução de Euler por meio da extensão referida do programa Oasis Montaj 5,06 da Geosoft.

Posteriormente à etapa de processamento, retirou-se da estimativa de profundidade das ocorrências a altura nominal de vôo de 45 metros da plataforma de aquisição. As 99 ocorrências que apresentaram profundidades negativas ou iguais a zero foram excluídas. A freqüência das ocorrências de acordo com a profundidade estimada apresenta uma distribuição log-normal. Assim, calculou-se o valor logarítmico das profundidades e subseqüentemente, a curva de freqüência das profundidades logarítmicas apresentou distribuição normal. Esse procedimento permitiu com que as ocorrências fossem reclassificadas em 7 classes de acordo a média \pm o desvio padrão do logaritmo da profundidade estimada (Figura 6).

A área estudada é coberta pelos sensores TM/LANDSAT-5 e ETM+/Landsat7, trajetória de órbitas WRS 217 e 218, ponto 74 datadas de 27/04/2001 e 11/08/1999, respectivamente, e compostas pelas bandas $1,2,3,4,5,7$ e 8 . O azimute solar da cena $218 / 74$ é de $44,78^{\circ}$ com elevação solar de $42,23^{\circ}$. O préprocessamento engloba as etapas de correção geométrica, correção atmosférica, montagem dos mosaicos das cenas e recorte da área de interesse.

Neste trabalho utilizou-se uma imagem Radarsat, modo Standard 7 (S7), adquirida em 07 de janeiro de 1997. A cena, correspondente à órbita 6142 descendente, foi obtida com polarização $\mathrm{HH}$, comprimento de onda da banda $\mathrm{C}(5,7 \mathrm{~cm})$, resolução aproximada de 25 metros e ângulo de incidência variando entre $45^{\circ}$ (near range) e $49^{\circ}$ (far range). As etapas de pré-processamento envolveram a ortorretificação da imagem por meio do modelo digital de elevação e recorte da área de interesse (Figura 3-C).

Os dados planialtimétricos utilizados compõem curvas de nível topográficas, cotas altimétricas e cursos d'água das cartas topográficas 1:50.000 de Belo Horizonte (MI-2535-3), Caete (MI-2535-4), Rio Acima (MI-2573-1), Acuruí (MI-2573-2), Cata Altas (MI-2574-1), Ouro Preto (MI-2573-4) e Mariana (MI-2574-3). A única carta em escala 1:100.000 utilizada foi a de Itabira (MI-2536) porque não existe levantamento em escala 1:50.000 na parte nordeste da área de estudo. Esses dados foram digitalizados e interpolados para criar o modelo digital de elevação (DEM) com resolução espacial de 30 metros. O método de interpolação escolhido foi a rede irregular de triângulos (TIN) (Figuras 3-E e 3-F).

O mapa geológico utilizado neste trabalho resulta do projeto Rio das Velhas (Pinto, 1996) em escala 1:100.000 editado pelo consórcio DNPM/CPRM e está no modelo vetorial formato 


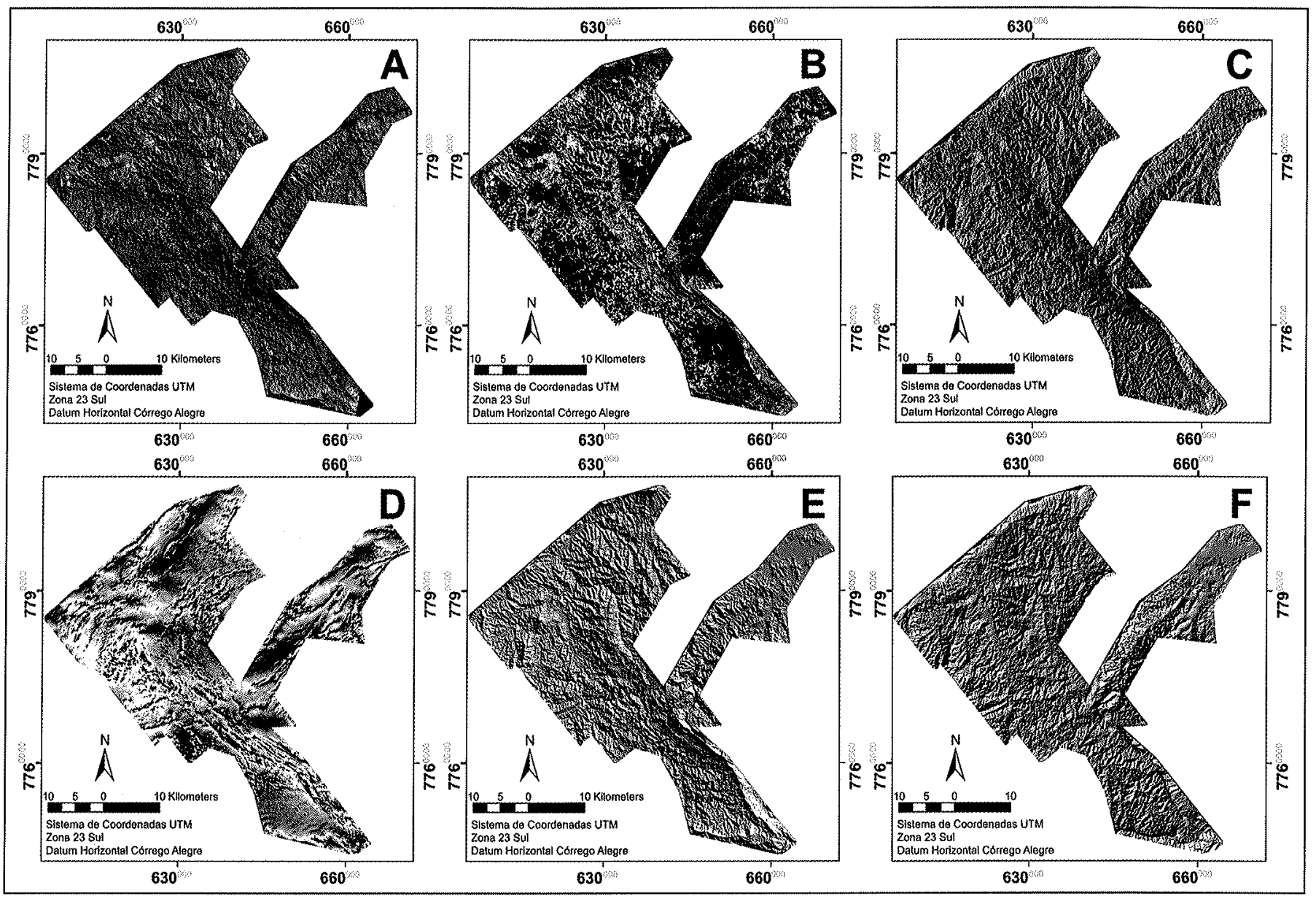

Figura 3 - (A) Banda pancromática do ETM+/Landsat 7. (B) Primeira componente principal das bandas 1,2, 3, 4, 5 e 7 do ETM+/Landsat 7. (C) Imagem de radar Scansar Standard (D) Fase do sinal analitico do campo magnético anômalo. (E) Modelo Numérico de Elevação (DEM) iluminado sinteticamente na direção 44,78 e elevação $42,23^{\circ}$ (F) Modelo Numérico de Elevação (DEM) iluminado sinteticamente na direção $135^{\circ}$ e elevação $42,23^{\circ}$

shapefile da Environmental System Research Institute (ESRI).

Técnicas de processamento digital de imagens tais como o realce por composição colorida falsa-cor RGB, análise por componentes principais, classificação não supervisionada por k-médias e, principalmente, transformação IHS foram aplicadas aos dados aerogeofísicos e de sensoriamento remoto.

FOTOANÁLISE A fotoanálise utilizada neste trabalho divide-se em duas etapas. A primeira consiste na extração de feições lineares de análise das formas da rede de drenagem, de relevo e de relevo magnético e na delimitação de domínios ou zonas homólogas geofísicas. A segunda etapa consiste na caracterização desses domínios geofísicos quanto às formas da rede de drenagem, do relevo, do relevo magnético e das estimativas de profundidade de fontes magnéticas por deconvolução de Euler. Por fim, determinam-se as assinaturas dos domínios geofísicos a partir das assinaturas magnéticas, condutivas e gamaespectrométricas.

Para este trabalho, utilizou-se o termo "lineamento" que caracteriza feições lineares extraídas de imagens de sensoriamento remoto e, por extensão, de imagens aerogeofísicas. Não se utiliza o termo lineações (Soares \& Fiori, 1976) pois este termo é normalmente utilizado para designar feições lineares em minerais em escalas de afloramento e microscópicas e o seu emprego para feições extraídas a partir de imagens gera certa confusão.

A primeira etapa da fotoanálise começa com a extração das feições lineares da rede de drenagem. Para isso, Veneziani \& Anjos (1982) sugerem a digitalização dessa rede a partir de car- tas topográficas. Se a escala da carta topográfica for menor do que a escala de trabalho, pode-se redigitalizar essa rede a partir de uma imagem que forneça a escala apropriada. $O$ produto intitulado "Estéreo por Disparidade Cromática do Relevo", ou EDICROM-R, constituído pela fusão da banda pancromática do $\mathrm{ETM}+$ no canal de intensidade de uma imagem em pseudo-cor do modelo digital de elevação, fornece uma excelente base para esse tipo de trabalho. A estereoscopia desse produto por meio de lentes dicróicas, ou Chromadepth ${ }^{T M}$ (Toutin \& Rivard, 1995 e Toutin, 1997) supre a deficiência que as imagens de satélite de média resolução espacial possuem em relação à extração dos canais de $1^{\text {a }}$ ordem, como salientam Veneziani \& Anjos (1982). Essa técnica de estereoscopia por disparidade cromática é possível por meio de óculos com lentes especiais (Chromadepth ${ }^{\mathrm{TM}}$ 3-D) que mostram os objetos em diferentes profundidades de acordo com as suas cores. As lentes Chromadepth ${ }^{\mathrm{TM}}$ 3-D mudam a direção da luz que a atravessa de acordo com a sua cor, ou comprimento de onda. A sensação de profundidade diminui à medida que se aumenta o comprimento de onda da luz. Assim, a profundidade dos objetos decresce de acordo com a seguinte escala de cores: azul, ciano, verde, amarelo, laranja e vermelho.

Outra imagem que pode ser utilizada para a extração das drenagens é originada da transformação IHS da imagem de composição colorida falsa-cor RGB/TM7, 4 e 3 com o modelo digital de elevação sombreado no canal de intensidade. Os parâmetros de iluminação utilizados são os mesmos da cena do ETM+/Landsat calculados para a data de aquisição: azimute solar de $44,78^{\circ}$ 


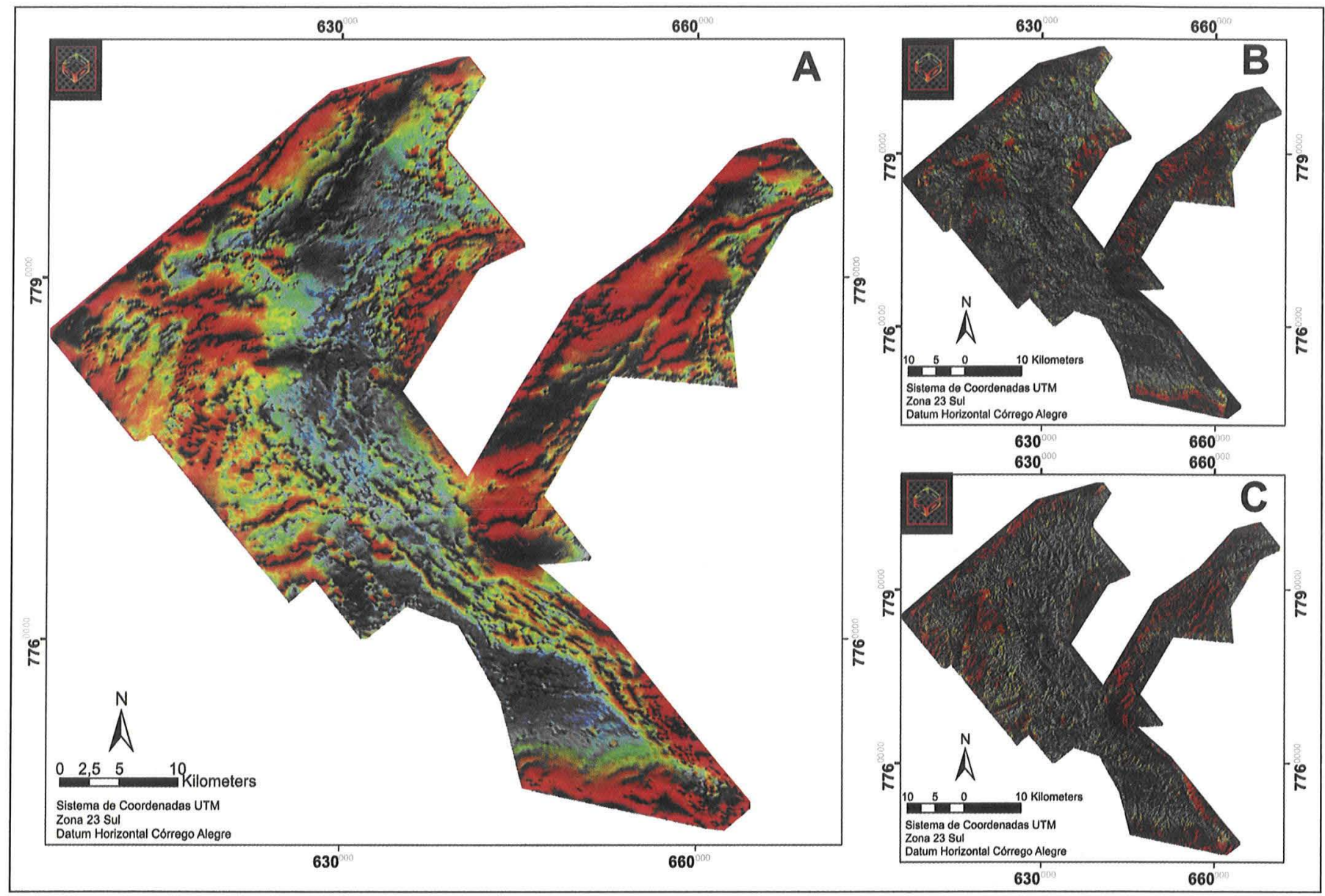

Figura 4 - Transformação IHS da amplitude do sinal analítico do campo magnético anômalo em pseudocor. (A) EDICROM-RM - fase do sinal analítico do campo magnético anômalo no canal de intensidade. (B) Banda pancromática do ETM+/Landsat 7 no canal de intensidade. (C) imagem de radar Scansar Narrow no canal de intensidade.

e elevação de $42,33^{\circ}$. Esse produto fundido visa realçar a iluminação do relevo na imagem. Dando continuidade ao trabalho, digitalizou-se os cursos d'água de cartas topográficas na escala 1:50.000 a partir dos produtos citados acima.

Extraiu-se as principais feições lineares de análise das formas de relevo como lineamentos. Os produtos integrados utilizados para extrair as feições de relevo são o EDICROM-R com a banda pancromática (Figura 3-A), modelo digital de elevação sinteticamente sombreado (Figura 3-B) ou a imagem de radar no canal de intensidade (Figura 3-C). Por fim, o modelo digital sombreado utiliza iluminação sintética com azimutes de $44,78^{\circ}$ e $135^{\circ}$ com elevação de iluminação igual ao do ETM+/Landsat 7 (Figuras 3-E e 3-F). Ou seja, com esses produtos pode-se realçar estruturas de direção noroeste (ETM+/Landsat 7), lesteoeste (radar) e nordeste (DEM sombreado).

Dentre as imagens derivadas do ETM+/Landsat 7 utilizadas no canal de intensidade do EDICROM-R, a banda pancromática apresenta melhor resultado para extração das feições lineares, visto que essa banda possui maior resolução espacial e a integração com a primeira componente principal mascara muitas estruturas devido à variação de tonalidade na imagem. As visadas em perspectiva do modelo digital de elevação auxiliam bastante o traçado dessas feições, principalmente no que diz respeitos às visadas em perspectivas que tenham sobrepostas imagem de composição colorida falsa-cor RGB/TM3, 2 e 1 ou esta fundida com a imagem de radar.

Para este trabalho, analisaram-se os lineamentos existentes nos relevos magnéticos e topográficos. O relevo magnético refe- re-se ao campo magnético anômalo, onde a extração das feições lineares é auxiliada pelas transformações lineares desse campo, principalmente pela amplitude do sinal analítico, que demarca a posição de fontes magnéticas. A fase do sinal analítico (Figura 2-D) possui um padrão textural que é de suma importância na caracterização da textura dos domínios magnéticos e na extração dessas feições lineares. A utilização das derivadas, principalmente das verticais, ajuda na compreensão das posições espaciais relativas das fontes magnéticas. Assim, o melhor produto integrado para extrair as feições lineares do relevo magnético consiste da transformação IHS da imagem pseudocor da amplitude do sinal analítico com a sua fase no canal de intensidade, intitulada neste trabalho de Estéreo por Disparidade Cromática do Relevo Magnético, ou EDICROM-RM (Figura 4-A, Teixeira 2003). Nesse produto, o elemento textural caracteriza-se pela sombra observada na imagem que apresenta os menores valores da fase do sinal analítico.

A delimitação dos domínios geofísicos pode-se basear em diversos produtos de imagens integradas. A utilização de cada produto depende da natureza da assinatura dos domínios que são separados em gamaespectrométricos, magnetométricos ou condutivos. Assim, pode-se citar os produtos da transformação IHS de composições coloridas falsa-cor, como por exemplo RGB/KTh-U, RGB/Amplitude do sinal analítico-condutividade-canal de contagem total, ou de imagens pseudocor, como a amplitude do sinal analítico e canal de condutividade, com a fase do sinal analítico ou a primeira derivada vertical no canal de intensidade. Uma outra opção é delimitar os domínios geofísicos analisando- 


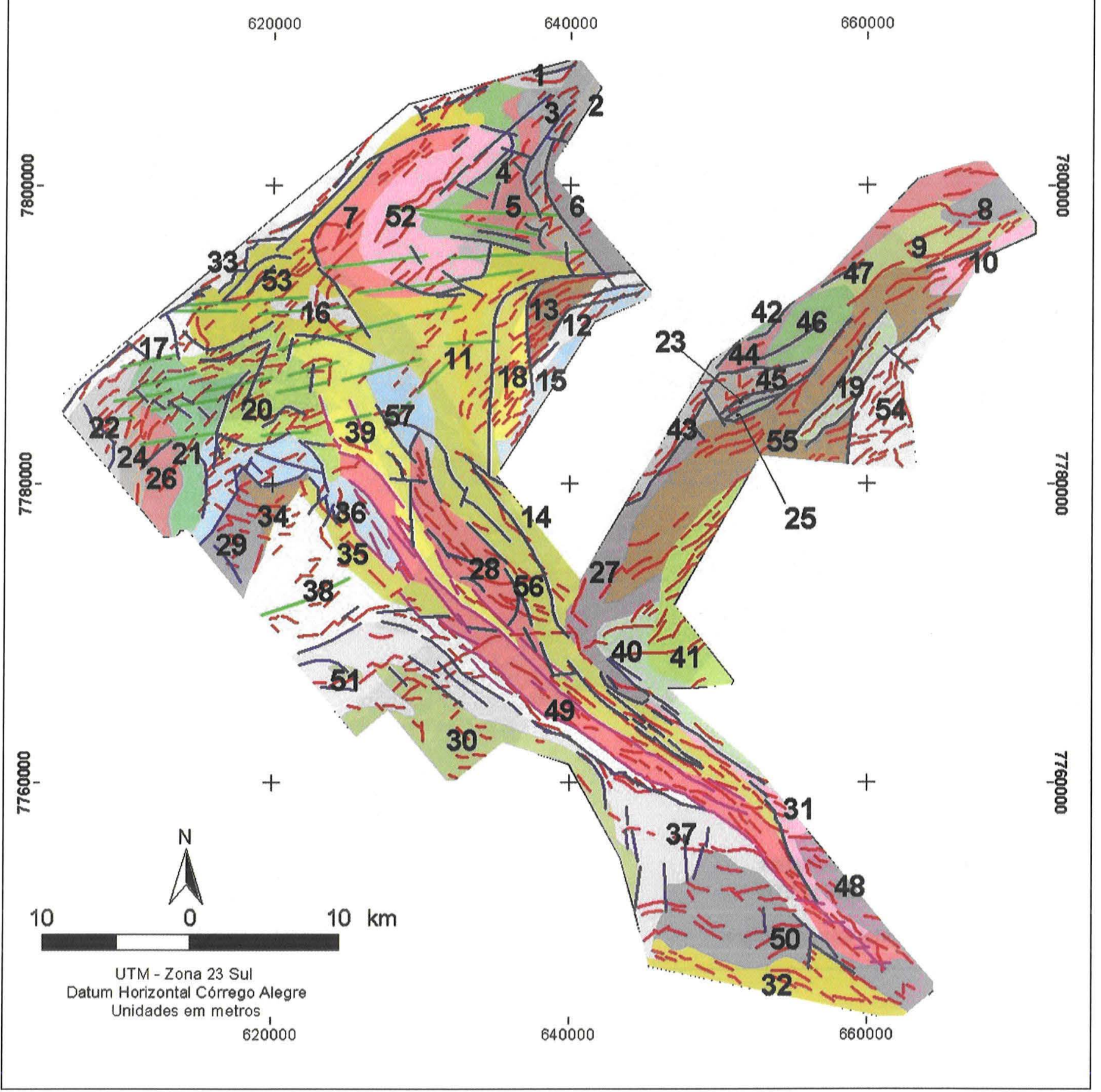

Figura 5- Mapa de interpretação das unidades litogeofisicicas e de interpretação estrutural. Legenda: Linhas Verde - Estruturas Direcionais, Linhas Azuis - Estruturas indiferenciadas, Linhas Vermelhas - Lineamento magnético, Linhas Magentas - Estruturas relacionas à Zona de Cisalhamento São Vicente. As cores dos polígonos diferenciam as unidades litogeofisicas.

se todas as assinaturas ao mesmo tempo. Um excelente produto que sintetiza todas essas informações é a classificação não supervisionada de todas as imagens geofísicas.

Ressalta-se que os produtos frutos da transformação IHS de imagens geofísicas com a primeira componente principal de imagens multiespectrais, radar, fase do sinal analítico ou primeira derivada vertical do campo magnético anômalo no canal de intensidade facilitam a delimitação dos domínios geofísicos, visto que as feições geomorfológicas "magnéticas" estão diretamente relacionadas aos domínios litológicos (Pinto \& Silva 1996) e litogeo- físicos. As imagens geofísicas mais utilizadas para esse propósito são a composição colorida $\mathrm{RGB} / \mathrm{K}-\mathrm{Th}-\mathrm{U}$, a imagem resultante da classificação não supervisionada por k-médias das imagens geofísicas e as imagens pseudocor da amplitude do sinal analítico e do canal de condutividade (Teixeira 2003)

Ao se traçar os domínios litogeofísicos, deve-se levar em consideração também o lixiviamento do potássio e do urânio que ocorre pelo transporte dos argilo-minerais (Gunn 1998). Assim, deve-se evitar traçar domínios que apresentem concentração desses elementos ao longo de drenagens. Outra característi- 


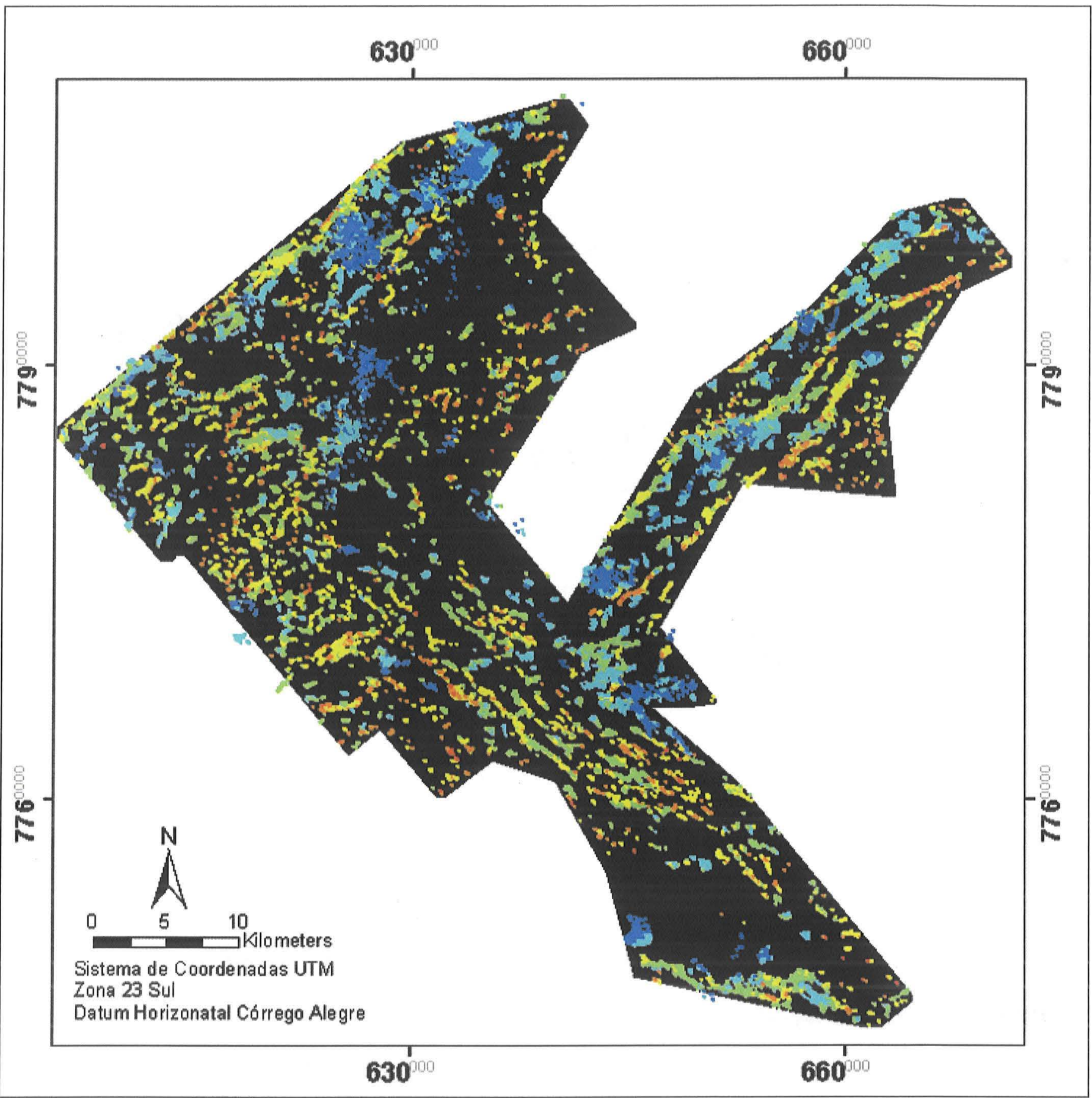

Figura 6-Mapa das estimativas de profundidade de fontes magnéticas por Deconvolução de Euler-3D. Legenda: Intervalo da Profundidade Estimada (metros): 0 - 62-Muito Raso (ciano), 62-119-Raso (verde), 19-230-Pouco Raso (azul), 230-436-Pouco Profundo (amarelo), 436 - 852-Profundo (amarelo), 852 - 1643-Médio Profundo (laranja), 1643 - 3706-Muito Profundo (vermelho)

ca importante a ser destacada é que a delimitação dos domínios geofísicos também leva em consideração os lineamentos extraídos na análise das formas de relevo e de relevo magnético.

Normalmente, a fotoanálise geológica leva em consideração a delimitação de zonas homólogas de acordo com as formas de drenagem, de relevo, tonalidade e textura. Para esse trabalho, a fotoanálise baseiou-se nas formas de drenagem, relevo topográfico, relevo magnético, tonalidade, textura topográfica, textura magnética e geometria das estimativas de profundidade de fontes magnéticas obtidos por deconvolução de Euler-3D.

Portanto, a segunda etapa da fotoanálise começa com a classificação dos domínios geofísicos a partir da análise das formas da rede drenagem. As principais propriedades texturais em análise são a densidade (baixa, média e alta), a sinuosidade (curvos, mistos e retilíneos), a tropia (unidirecional, bidirecional, tridirecional e multidirecional, desordenadas ou ordenadas) e a assimetria (fraca e forte). Para simplificar a análise, não se consideram a angularidade (Soares \& Fiori 1976, Veneziani \& Anjos 1982)e o ângulo de junção nem o grau de interação (Lima 1995). Para caracterizar a forma de drenagem a partir das propriedades texturais classifica-se a rede a partir da densidade de textura (baixa, média e alta), do grau de estruturação (muito fraco, fraco, moderado, forte e muito forte) (Lima 1995) e da ordem de estruturação ( $1^{\mathrm{a}}$ e $2^{\mathrm{a}}$ ordens). Por fim, classificase a rede de drenagem quanto à sua estrutura (Soares \& Fiori 1976, Veneziani \& Anjos 1982) em dendrítica, paralela, treliça, 
retangular, radial, anelar, multibacinal, contorcido, complexo e palimpsesto. $O$ produto principal que auxilia a compreensão da forma da rede de drenagem é o produto EDICROM-R com a banda pancromática do sensor ETM+/Landsat7(Figura 2-A), a imagem de radar(Figura 2-B) e o Modelo Digital de Elevação sombreado(Figura 2-C).

A classificação dos domínios geofísicos a partir da análise das formas de relevo e relevo magnético baseia-se nas propriedades texturais de relevo (Soares \& Fiori 1976, Veneziani \& Anjos 1982) como densidade (baixa, média e alta), assimetria (fracamente assimétrico, moderadamente assimétrico, fortemente assimétrico e simétrico) e lineamentos. A caracterização das formas de relevo envolve a densidade (baixa, média e alta), a estruturação, o grau de estruturação (muito fraco, fraco, moderado, forte e muito forte) e a ordem de estruturação ( $1^{\mathrm{a}}$ e $2^{\mathrm{a}}$ ordem). Como acontece com a análise da forma da rede de drenagem, o melhor produto para essa finalidade é o EDICROM-R com a banda pancromática do sensor ETM+/Landsat7 (Figura 2-A), a imagem de radar (Figura 2-B) ou modelo digital de elevação sombreado (Figura 2-C). Já para a análise da forma do relevo magnético, o melhor produto é o EDICROM-RM (Figura 4-A).

Posteriormente, classificam-se os domínios geofísicos a partir da caracterização da geometria das estimativas de profundidade por meio da deconvolução de Euler-3D de acordo com a densidade (baixa, média e alta), a profundidade, a estruturação, o grau de estruturação (muito fraco, fraco, moderado, forte e muito forte) e a ordem de estruturação $\left(1^{a}, 2^{a}, 3^{a}\right.$ e $4^{a}$ ordem). $O$ melhor produto para se fazer essa análise é a disparidade cromática, que fornece noção tridimensional das estimativas de profundidade. Esse produto mostra a variação do acervo estrutural e sua continuidade em subsuperfície.

Depois de classificar os domínios geofísicos de acordo com a análise da forma da rede de drenagem, do relevo e do relevo magnético, eles são reclassificados de acordo com a intensidade da assinatura geofísica, seja ela a intensidade da amplitude do sinal analítico, condutividade ou variação dos radioelementos $\mathrm{K}$, Th e U. Desse modo, estipula-se uma escala qualitativa ordinal classificada em baixo, médio e alto valor.

Outra característica a ser descrita diz respeito à textura do relevo e do relevo magnético aqui representado pelas imagens de radar e pelo produto EDICROM-RM, respectivamente. $O$ elemento textural da imagem de radar definido por Lima (1995) é exemplificado por um entre vários morros de mesma cota, forma e disposição espacial, ou seja, a sombra do relevo radargráfico. Já no produto EDICROM-RM, os valores negativos da fase do sinal analítico, no canal de intensidade, são os responsáveis pela textura. Desse modo, aplica-se esse mesmo conceito só que ao invés da sombra radargráfica, o elemento textural é caracterizado pelos valores negativos da fase. Numa tentativa de se classificar o relevo magnético em categorias, Blum (1999) classifica o relevo magnético em suave, acidentado incorrelato, acidentado correlato e muito acidentado. A nomenclatura da classificação da textura de radar adotada neste trabalho é a classificação em termos relativos (fina, média e grossa) (Lima 1995) estendida para o produto EDICROM-RM.

Para este trabalho, os domínios analisados foram guiados pela classificação não supervisionada por k-médias dos canais de potássio, tório, urânio, amplitude do sinal analítico e condutividade no canal de $4.175 \mathrm{~Hz}$, com 10 classes e 10 interações.

FOTOINTERPRETAÇÃO A fotointerpretação envolveu a interpretação dos domínios extraídos da análise da forma dos elementos naturais, conforme apresentado anteriormente, complementado com a interpretação geofísica. Classificam-se as feições lineares do relevo e do relevo magnético em estruturas direcionais, lineamentos indiferenciados, lineamentos de relevo magnético e estruturas das zonas de cisalhamento São Vicente. A validação destas estruturas foi feita pela comparação com as estruturas mapeadas pelo Projeto Rio das Velhas (Escala 1:100.000) (Pinto, 1996).

Correlação das Unidades Litogeofísicas com as Unidades Litológica A partir do mapa litológico do Projeto Rio das Velhas pode-se correlacionar as unidades litogeofísicas extraídas na fotoanálise e entender o seu significado. Aqui, sumarizam-se as unidades interpretadas na Figura 5 e sua correlação com o mapa geológico na escala 1:100.000. Observa-se que o número de domínios mapeados e interpretados com os dados multifontes revela variações que não estão presentes no mapa geológico.

De uma forma geral, as unidades litogeofísicas que se correlacionam com as rochas máficas-ultramáficas do Grupo Nova Lima apresentam baixos valores de radiação e média a alta intensidade dos gradientes magnéticos e valores de condutividade. Porém, a partir da análise das formas de drenagem, relevo, relevo magnético e das estimativas de profundidade de fontes magnéticas por deconvolução de Euler-3D pode-se individualizar cada unidade separadamente. Assim, a unidade litogeofísica 54 que se correlaciona com a Formação Quebra-Osso diferencia-se das demais por apresentar moderado grau de estruturação das formas de drenagem e relevo e primeira ordem de estruturação de drenagem e relevo. A unidade litogeofísica que se correlaciona com a Formação Córrego dos Boiadeiros se diferencia principalmente por possuir alta densidade e forte estruturação das estimativas de profundidade de fontes magnéticas rasas a médio profundas (60 a $1640 \mathrm{~m}$ ) e fina texturas das imagens de radar e do relevo magnético. Já a principal característica das unidades litogeofísicas que se correlacionam com a Formação Córrego do Ouro Fino é a sinuosidade das drenagens e o fraco grau e baixa ordem de estruturação das estimativas de profundidade de fontes magnéticas muito rasas a profundas $(0-850 \mathrm{~m})$. Mesmo assim, pode-se observar variações dentro dessa formação em relação às outras características analisadas, como por exemplo, a textura das imagens de radar e do relevo magnético.

A Formação Morro Vermelho se correlaciona com as unidades litogeofísicas que apresentam valores altos de radiação de potássio, valores médios de tório e urânio, valores baixos a médios do gradiente magnético e valores baixos de condutividade. Porém, a unidade litogeofísica 20, apesar de se correlacionar espacialmente com a Formação Morro Vermelho, apresenta valores médios de radiação e valores altos de gradiente magnético e de condutividade. Outra característica discrepante é o padrão de drenagem dendrítico que se diferencia das demais unidades porque apresenta padrão complexo ou em treliça.

Formação Santa Quitéria se correlaciona com a unidade litogeofísica 19 e apresenta baixos valores de radiação de potássio e tório, médios valores de radiação de urânio, alta intensidade dos gradientes de magnetização e baixa condutividade. A característica mais marcante dessa unidade é a textura grossa na imagem de radar e do relevo magnético.

As rochas metassedimentares vulcanogênicas do Grupo Nova Lima, representado pela Formação Mestre Caetano, se correlaciona com as unidades litogeofísicas 26, 39 e 53 que apresentam altos valores de radiação de potássio, médios valores de radiação de urânio e baixos gradientes magnéticos e de condutividade. Apresentam forte grau e alta ordem de estruturação das estimativas de profundidade de fontes magnéticas rasas a médio-profundas $(60 \mathrm{a} 1600 \mathrm{~m})$. Outra característica marcante dessas unidades litogeofísicas é o padrão de drenagem em treliça ou paralela.

A Formação Ribeirão Vermelho se correlaciona com a unidade litogeofísica 4 que possui altos valores de radiação e baixos valores de gradiente magnético e de condutividade. Essa 
unidade apresenta textura lisa do relevo magnético e textura média da imagem de radar. Sua principal característica é o fraco grau de estruturação, porém, possui alta ordem de estruturação das estimativas de profundidade de fontes magnéticas muitorasas a muito-profundas ( 0 a $3700 \mathrm{~m}$ ).

As unidades litogeofísicas que se correlacionam com a Formação Córrego do Sítio possuem médios a baixos valores de radiação de potássio, baixo a médios valores de radiação de tório e urânio, média intensidade dos gradientes magnéticos e altos ou baixos valores de condutividade. Por serem muito extensas, as unidades litogeofísicas que se correlacionam espacialmente com essa formação se diferenciam muito. Outra característica comum a essas unidades é a textura da imagem de radar que varia de média a grossa. A textura do relevo magnético varia de fina a grossa. As unidades ainda apresentam forte grau e alta ordem de estruturação das estimativas de profundidade de fontes magnéticas.

As formações Catarina Mendes, Córrego da Paina, Fazenda Velha e Pau D'óleo se correlacionam com as unidades litogeofísicas 37 e 50 que se caracterizam por baixo a médios valores de radiação de potássio, médios valores de radiação de tório e urânio e baixos a médios valores de gradiente magnético e de condutividade. Ambas as unidades possuem textura lisa do relevo magnético e média a grossa textura da imagem de radar. A unidade litogeofísica 50 é continua à unidade 37 e está localizada mais ao sul da área, apresentando formas de drenagem e de relevo diferentes. Enquanto a unidade 37 possui forma de drenagem sinuosa, tridirecional e padrão em treliça, a unidade 50 apresenta drenagens retilíneas, bidirecionais e dendríticas.

Contatos Geológicos Os melhores produtos para delimitar os domínios litogeofísicos englobam a rede de drenagem e a fusão da imagem da classificação não supervisionada com as imagens da primeira componente principal ou banda pancromática do sensor ETM+, radar ou fase do sinal analítico, ambos no canal de intensidade. O produto EDICROM-R com a primeira componente principal e o radar no canal de intensidade auxilia na caracterização desses limites. Como dito anteriormente, a interpretação desses produtos se complementa, visto que essas imagens apresentam diferentes ângulos de azimute de iluminação do relevo. Outra característica a ser ressaltada é que a variação de tons observada na primeira componente principal e a textura observada na imagem de radar auxiliam a delimitação desses domínios.

Quanto à natureza do contato entre os domínios, o contato tectônico é bem representado no produto EDICROM-R com a banda pancromática do sensor ETM+ no canal de intensidade porque apresenta feições de relevo distinguíveis, enquanto que a análise das formas da rede de drenagem permite a delimitação do contato litológico.

Feições Estruturais O melhor produto resultante da transformação IHS para interpretação estrutural de estruturas em subsuperfície é o EDICROM-RM (Figura 4-A). Assim, ao mesmo tempo em que se identifica a posição da fonte magnética, pode-se identificar uma assinatura do mergulho do gradiente da anomalia.

O melhor produto para fotointerpretação de estruturas com expressão superficial é o EDICROM-R com a imagem de radar(Figura 2-C), a banda pancromática do ETM+/Landsat (Figura 2-A) ou o modelo digital de elevação sombreado (Figura 2-B) no canal de intensidade. A primeira componente principal não é melhor que as outras imagens porque a variação tonal nessa imagem mascara bastante as feições lineares relacionadas às estruturas.

A transformação IHS da imagem pseudocor da amplitude do sinal analítico com as imagens que refletem as feições superfi- ciais como a imagem de radar (Figura 4-C), ETM+/Landsat 7 (Figura 4-B) e modelo digital de elevação no canal de intensidade representa um produto intermediário, o qual pode ser utilizado para analisar a continuidade em subsuperfície de estruturas de expressão geomorfológica.

A partir da análise dos principais produtos para fotointerpretação estrutural foi possível individualizar quatro conjuntos de estruturas. $\mathrm{O}$ primeiro corresponde às estruturas direcionais de sentido aproximadas leste-oeste que aparecem no norte da área. Outro conjunto de estruturas está relacionado aos lineamentos do relevo magnético. $O$ terceiro conjunto de estruturas está diretamente relacionado à Zona de Cisalhamento São Vicente. $\mathrm{O}$ último conjunto de estruturas refere-se às estruturas indiferenciadas observadas na região.

Analisando-se o EDICROM-RM (Figura 4-A), observa-se que ao longo da Zona de Cisalhamento São Vicente os valores da fase do sinal analítico variam muito, como conseqüência da variação do mergulho da falha validada pelos trabalhos de mapeamento ao longo da mesma (Araújo 2001). As estimativas de profundidade das fontes magnéticas por meio da deconvolução de Euler auxiliam o entendimento do comportamento geométrico dessa falha em profundidade. No geral, a falha apresenta pouca profundidade $(200 \mathrm{a} 400 \mathrm{~m})$ com algumas áreas profundas (400 a $800 \mathrm{~m})$. As áreas mineralizadas de ouro ao longo da falha apresentam assinatura padrão com valores de fase do sinal analítico próximos a zero.

Dentre as estruturas interpretadas como lineamentos indiscriminados, pode-se ressaltar as estruturas de sentido norte-sul que se observam no sul da área. Estas estruturas são bastante realçadas nas imagens derivadas da fusão com a imagem de radar. Essas estruturas foram identificadas por Silva (1999) a partir do mapa reduzido ao pólo e nos seus produtos derivados. Já as estruturas de direção nordeste são bastante ressaltadas pelas imagens derivadas da fusão do modelo digital de elevação sombreado com azimute de iluminação sintética de $135^{\circ}$ (Figura 3-F).

CONCLUSÃO Observam-se diferenças entre litotipos mapeados no Projeto Rio das Velhas e a interpretação efetuada no presente trabalho, principalmente no que diz respeito à disposição espacial das unidades litológicas em relação às unidades litogeofísicas.

Nos produtos derivados da transformação IHS para fotointerpretação geológica, a transformação IHS das imagens aerogeofísicas com a primeira componente principal do $\mathrm{ETM}+/$ Landsat 7 ou a imagem de radar ou a banda pancromática do ETM+/Landsat 7 ou o modelo digital de elevação sombreado no canal de intensidade possibilitam a delimitação de unidades litogeofísicas e a extração de estruturas.

No que se refere à delimitação de unidades litogeofísicas, a transformação IHS das imagens aerogeofísicas com a primeira componente principal do ETM+/Landsat 7 no canal de intensidade apresenta um excelente resultado pois agrega feições geomorfológicas às informações fornecidas pela variação lateral geofísica das unidades litológicas. A partir desse produto podem-se diferenciar domínios com mesma resposta geofísica, mas que representam diferentes condições de concentração, como exemplo, a lixiviação de elementos como potássio e urânio ao longo de drenagens. A utilização da primeira componente principal no canal de intensidade mostra-se superior à utilização da imagem de radar ou da banda pancromática no que se refere à separação de domínios litogeofísicos. Isto se deve à variação tonal mais significativa decorrente da correlação das bandas do ETM+/Landsat 7 na primeira componente principal.

Para a extração de feições lineares estruturais, destacam-se o EDICROM-R, EDICROM-RM e os produtos originados da transformação IHS da imagem da amplitude do sinal analítico 
e do canal de condutividade com a imagem de radar ou a banda pancromática do ETM+/Landsat 7 ou o modelo digital de elevação sombreado no canal de intensidade.

A diferença do ângulo de iluminação do relevo nessas imagens, e em específico do modelo digital de elevação sombreado com azimute $135^{\circ}$, permite a extração e a complementação das informações estruturais na região, como as estruturas de direção norte-sul observadas no sul da área e dos lineamentos indiscriminados de direção nordeste.

A partir da análise textural do EDICROM-R e dos lineamentos das estimativas de profundidade da deconvolução de Euler pode-se identificar zonas homólogas ao longo da Zona de Cisalhamento São Vicente, que refletem a variação do ângulo de mergulho dessa falha.

\section{Referências}

Araújo J. G. M. 2001. Influência das zonas de cisalhamento de São Vicente e Tapera na mineralização aurifera do Quadrilátero Ferrifero, Minas Gerais. Dissertação de mestrado Instituto de Geociências. Universidade de Brasília. Brasília, $100 \mathrm{p}$.

Blum M.L.B., 1999. Processamento e Interpretação de Dados de Geofisica Aérea no Brasil Central e sua Aplicação à Geologia Regionale à Prospecção Mineral. Tese de Doutoramento, Inst. de Geociências, Universidade de Brasília, Brasília.

Dorr II J.V.N. 1969. Physiografic, stratigraphic, and structural development of the Quadrilátero Ferrifero, Minas Gerais. U.S.G.S. Paper, v. $641-A, p .1-110$

Drury S.A. 1993. Image Interpretation in Geology. Chapman \& Hall, London.

Duarte M.I.M. 1998. Análise Integrada de Dados Aplicada à Geologia do Supergrupo Rio das Velhas (NE do Quadrilátero Ferrifero). Dissertação de mestrado, IG, Unicamp, Campinas, $80 \mathrm{p}$.

Ferreira F.J.F. Bicho C.P. Crósta A.P. Vasconcellos R.M. 1993. Aplicação e técnicas de processamento digital de imagens na interpretação geológica de um trato SE de Rondônia. In: Congresso Internacional da Sociedade Brasileira de Geofísica, 3, atas, SBGf. 809-813.

Ford J.P., Blom R.G., Coleman J.R., Farr J.J., Plaut H.A., Pohn F.F., Sabins J.R. 1998. Radar Geology. In: Manual of Remote Sensing. 3 ed. New York, John Wiley \& Sns, 511-564.

Fuck R.F. 2000. Interpretação de dados magnetométricos, eletromagnetométricos e gamaespectrométricos da região de Carajás-PA. Dissertação de mestrado, IG/UnB, Brasília.

Gunn P.J. 1998. Interpretation of airborne magnetic and radiometric surveys. Course. AGSO. $150 \mathrm{p}$.

Lima M.I.C 1995. Introdução à Interpretação Radargeológica. Manuais Técnicos em Geociências, 3, IBGE, 124p.

Lima M.I.C. 1989. Metodologia da interpretação radargeológica. In: Simpósio Lationoamericano de Percepcion Remote, 4, Argentina, Bariloche, Atas, 629-639.

Liu C.C. \& Rodrigues J.E. 1985. Radargeologia. São José dos Campos, INPE, $45 p$.

Nash C., Leeming P., Kotasek H., Carey R. 1996. Integrated interpretation of imaged airborne geophysical survey and remote sensing data with the aid of vectorised CAD/GIS coverages: Halls Creek Mobile Belt, Australia. In: Thematic Conference and Workshops on Aplied Geologic Remote Sensing, 11, Las Vegas, Nevada.

Paradella W.R., Pietsch R.W., Toutin T. 1997. Airborne and spaceborne synthetic aperture radar (SAR) integration with Landsat TM and gamma ray spectrometry for geological mapping in a tropical rainforest environment, the Carajás Mineral Province, Brazil. Int. J. Remote Sensing, 18(7):1483-1501.

Paradella W.R., Santos A.R., Dall'Agnol R., Pietsch R.W., Sant'Anna M.V. 1998. A Geological investigation based on airborne (SAREX) and spaceborne (RADARSAT-) SAR integrated products in the Central Serra dos Carajás Granite Area, Brazil. Canadian Journal of Remote Sensing, 24(4):376-392.

Paradella W.R. Santos A.R. Veneziani P. Sant'Anna M.V. Morais M.C. 2000. Geological investigation using RADARSAT-1 images in the tropical rain forest environment of Brasil. Canadian Journal of Remote Sensing, 26(2):82-89.

Pedroso E.C., Rivard B., Crósta A.P., Souza Filho CR., Mirana E.P. 2001.
Reconnaissance geologic mapping in the Tapajós Mineral Province, Brazilian Amazon, using spaceborne SAR imagery and airborne geophysics. Canadian Journal of Remote Sensing, 27(06):669-678.

Pinto P.C. 1996. Explanatory notes/Rio das Velhas project. Rel. téc. DNPM-SUREG/BH.

Pinto P.C. \& Silva L.C. 1996. Contrasting tectono-stratigraphic domains in the Rio das Velhas Greenstone Belt (RVGB), MG, Brazil. In: SBG, Symposium Archaean Terranes of the South American Platform. Brasília, Anais, 23-25.

Reeves C.V., Reford S.W., Milligan P.R. 1997. Airborne geophysics: old methods, new images. In: A.G. Gubins (ed.) Proceedings of Exploration 97. Fourth Decennial International Conference on Mineral Exploration, 13-30.

Reid A.B., Allsop J.M., Granser H., Millett A.J., I.W. Somerton. 1990. Magnetic interpretatiom in three dimensions using Euler deconvolution. Annual International Meeting, 58, Society of Exploration Geophysicists.

Rivard B., Kellett R.L., Saint-Jean R., Singhroy V. 1994. Characterization of faulting and dyke intrusion in the Benny Formation Zone, North Range of Sudbury, from magnetics and SAR. Canadian Journal of Remote Sensing, 20:324-328.

Rivereau J.C. 1970. Fotinterpretação. Revista da Escola de Minas, Ouro Preto, 28(4):157-175.

Rolim S.B. A. 2001. Resposta Geofisica dos Depósitos de Ouro da Porção Central do Quadrilátero Ferrifero, $M G$. Tese de Doutoramento, Instituto de Geociências, Universidade Estadual de Campinas, Campinas.

Silva A.M. 1999. Geophysical and Geological Data Integration Using a New Statistical Approach for Mineral Target Selection Applied to the Rio das Velhas Greenstone Belt, Quadrilátero Ferrifero. Tese de Doutoramento, Inst. de Geociências, Universidade de Brasília, Brasilia.

Soares P.C. \& Fiori A. 1976. Lógica e sistemática na análise e interpretação de fotografias aéreas em geologia. Notícias Geomorfológicas, Campinas, 16(32):71-104.

Thompson D.T. 1982. EULDPH: A new technique for making computer-assisted depth estimates from magnetic data. Geophysics, 47:3137.

Toutin T. 1997. Qualitative aspects of chromo-stereoscopy for depth perception. Photogrammetric Engineering and Remote Sensing, 63(2):93-203.

Toutin T. \& Rivard B. 1995. A new tool for depth perception of multi-source data. Photogrammetric Engineering and Remote Sensing, 61(10):1209-1211.

Teixeira A.A. 2003. Integração de Dados Multifontes para Exploração Mineral de Ouro, Greenstone Belt Rio das Velhas, Quadrilátero Ferrifero, $M G$. Dissertação de mestrado, Instituto de Geociências, Universidade de Brasília, Brasília, 180p.

Veneziani P. \& Anjos C.E. 1982. Metodologia de Interpretação de dados de sensoriamento remoto e aplicações em geologia. São José dos Campos, INPE, 76p.

Manuscrito A-1608 Revisão aceita em 17 de outubro de 2006 